\title{
Would it be possible to have better ways and routes of administration for vaccines against COVID-19?
}

\author{
Álvaro Nagib Atallah', Samir Arbache" \\ Universidade Federal de São Paulo (UNIFESP), São Paulo (SP), Brazil
}

'MD, PhD. Full Professor and Head of the Discipline of Emergency Medicine and Evidence-Based Medicine, Universidade Federal de São Paulo (UNIFESP), São Paulo (SP); and Director of Cochrane Brazil, São Paulo (SP), Brazil. (D) https://orcid.org/0000-0003-0890-594X

"MD. Preceptor of Dermatology, Universidade de Mogi das Cruzes (UMC), São Paulo (SP), Brazil; and Doctoral Student, Postgraduate Program on Evidence-Based Healthcare, Department of Medicine, Universidade Federal de São Paulo (UNIFESP), São Paulo (SP), Brazil.

(D) https://orcid.org/0000-0003-4409-4937
Dear Editor,

While celebrating with joy the evidence of the effectiveness of several vaccines against coronavirus disease 2019 (COVID-19), we are faced with the reality that billions of people in all regions of the planet will need to be vaccinated in order to achieve plausible control of the pandemic.

Scientific debates on which vaccine would be the best for COVID-19 have been given priority by scientific publications and news reports, with less emphasis than necessary on discussion of what the best vaccine administration routes might be.

Until such time that better evidence is available, we believe that research on new routes of administration is as important as proving the individual effectiveness of each vaccine. In these times of a pandemic, this is an opportunity to carry out randomized clinical trials to test different types of intradermal immunization in comparison with intramuscular immunization.

As a covering organ, the skin has mechanisms to protect the organism against physical, chemical or biological aggressions. Keratinocytes, Langerhans cells, fibroblasts, T lymphocytes, macrophages and dendritic cells are the first line of defense in the immune, cellular or humoral response. ${ }^{1}$

This immunological defense is not observed in the hypodermis or in the underlying muscles. Consequently, it is assumed that cutaneous microbiomes would have the function of "educating" the body's immune system. ${ }^{2}$

Over recent years, injection of vaccines into the intradermal compartment has been considered. The logic is that vaccines injected into the dermis would provide greater immune stimulation. ${ }^{2}$

Several techniques for percutaneous immunizations have been described, among which three can be listed: superficial manual punctures with microneedles; intradermal Mantoux injection (the Mantoux method, which was first described in 1910 and has become the clinical standard for intradermal injection); and "DNA tattooing", described by Bins et al.in 2005. ${ }^{3}$ In our view, this last method could be the most effective technique in a national vaccination campaign. ${ }^{3}$

What are the differences between these intradermal vaccination techniques?

Manual punctures with microneedles consist of dripping the vaccine on the skin and puncturing the site with needles. The diffusion of the vaccine in the dermis is passive. ${ }^{2,4,5}$ Assuming that two dozen perforations should be performed on the skin of each patient, the procedure could be exhausting for the technician, thus losing effectiveness. ${ }^{6}$

Intradermal injection with a syringe and needle (Mantoux method) requires technical skill. Moreover, the volume that needs to be injected is greater, with the aim of forming a bolus.

DNA tattooing ${ }^{3}$ uses tattoo machines to inject vaccines into the skin instead of inks. This vaccine delivery method was inspired by the ancient technique of artistic dermopigmentation. It was innovated and implemented by Brazilian dermatologists eight years ago, under the name MMP (Portuguese-language acronym for Micro-Infusion of Drugs into the Skin). ${ }^{4-5}$

Tattoo machine procedures are accurate and reproducible. The protocol for injecting medications with tattoo machines has already been established, consisting of 570 perforations per $\mathrm{cm}^{2}$, with a needle speed of between $60 \mathrm{~Hz}$ and $120 \mathrm{~Hz}$ and a needle depth of 300 microns. ${ }^{5}$ The rapid movement of the needles causes diffusion and active dispersion of the vaccine in the dermis. ${ }^{4}$ 
This gives rise to a greater area of immunological exposure that may extend to regional lymph nodes.?

We estimate that to immunize a patient, we need to puncture $1 \mathrm{~cm}^{2}$ of skin. We performed an experimental assay (unpublished results) in which we injected $1.0 \mathrm{ml}$ of saline into artificial skin using a tattoo machine. This amount was enough to cover 20 to $50 \mathrm{~cm}^{2}$ of artificial skin, meaning that 20 to 50 patients could be immunized with this volume, depending on the skill of the technician.

We propose to launch randomized, well-designed clinical trials that will aim to describe the effectiveness of intradermal vaccination in its three forms and compare them with each other and with traditional intramuscular vaccination.

These studies may be carried out in different scenarios and be brought together later, in syntheses of appropriate evidence.

It is essential to carry out analyses on cost-effectiveness and budgetary impacts, and to explore the possibilities of attaining greater efficiency, in order to cope with limited resources and enable better access to treatments for less developed countries.

Through such studies, data for clinical decisions can be provided, so as to be better prepared to face the challenges of comprehensive worldwide immunization; and, of course, to improve patients' experience.

\section{REFERENCES}

1. Medzhitov R, Janeway C Jr. Innate immunity. N Engl J Med. 2000;343(5):338-44. PMID: 10922424; https://doi.org/10.1056/ NEJM200008033430506

2. Hettinga J, Carlisle R. Vaccination into the Dermal Compartment: Techniques, Challenges, and Prospects. Vaccines (Basel).2020;8(3):534. PMID: 32947966; https://doi.org/10.3390/vaccines8030534.

3. Bins $A D$, Jorritsma A, Wolkers $M C$, et al. A rapid and potent DNA vaccination strategy defined by in vivo monitoring of antigen expression. Nat Med. 2005;11(8):899-904. PMID: 15965482; https:// doi.org/10.1038/nm1264.

4. Arbache S, Mendonca MT, Arbache ST, Hirata SH. Treatment of idiopathic guttate hypomelanosis with a tattoo device versus a handheld needle. JAAD International. 2021;3:14-6. https://doi.org/10.1016/j. jdin.2021.01.005.

5. Arbache S, Mattos EDC, Diniz MF, et al. How much medication is delivered in a novel drug delivery technique that uses a tattoo machine? Int J Dermatol. 2019;58(6):750-5. PMID: 30828798; https://doi.org/10.1111/ ijd.14408.

6. Prausnitz MR, Mikszta JA, Cormier M, Andrianov AK. Microneedlebased vaccines. Curr Top Microbiol Immunol. 2009;333:369-93. PMID: 19768415; https://doi.org/10.1007/978-3-540-92165-3_18.
7. Hellerich U. Tätowierungspigment in regionären Lymphknoten-ein Identifizierungsmerkmal? [Tattoo pigment in regional lymph nodes--an identifying marker?] Arch Kriminol. 1992;190(5-6):163-70. PMID: 1482232.

Author's contributions: Atallah AN: conceptualization (equal), data curation (equal), writing-original draft (equal) and writing-review and editing (equal); Arbache S: conceptualization (equal), data curation (equal), writing-original draft (equal), writing-review and editing (equal) and final approval (lead). Both authors actively contributed to the production of the manuscript, revised and approved the final version to be published

\section{Sources of funding: None}

Conflict of interest: Samir Arbache: Tattooing is an ancient technique under public domain done mainly by tattoo artists. We have chosen to copyright the acronym MMP ${ }^{\circledR}$ in Brazil, United States and Europe and we grant free use exclusively to dermatologists who are members of the Brazilian Society of Dermatology and equivalent entities around the world. Dr Arbache's commercial involvement in this investigation was required in order to obtain approval of the equipment for medical use under Brazilian health legislation (as enforced by Agência Nacional de Vigilância Sanitária, ANVISA) and to render this investigation acceptable for the relevant ethics committee. We hereby inform that the clinical results described and documented herein can be achieved using any available tattoo machine. Dr Arbache is a member of the staff that trains Brazilian dermatologists in the use of this technique. Álvaro Nagib Atallah is an Adjunct Editor of the Sao Paulo Medical Journal

Date of first submission: April 16, 2021

Last received: April 16, 2021

Accepted: May 18, 2021

\author{
Address for correspondence: \\ Samir Arbache \\ R. Coronel Madeira, 45 \\ Centro — São José dos Campos (SP) - Brasil \\ CEP $12245-760$ \\ Tel. (+55 12) 98122-1011 \\ E-mail: samir@dermocentro.com.br
}

